And there's the rub. Electric cars, solar power, and carbon capture and storage are technologies heralded as part of our solution set. But to paraphrase American gunmakers, coal doesn't burn the planet; people do. Workman lays out the "seven habits of highly successful foragers". Number 7 is "Subordinate taste to survival." If more people could do that alone, our lifestyle might look less and less like a twentieth-century fossil.

Published online: 30 July 2009

doi:10.1038/climate.2009.74
Eric Roston

Eric Roston, author of The Carbon Age, is Senior Associate at the Nicholas Institute for Environmental Policy Solutions at Duke University. He writes a weekly climate news analysis at http://www.ClimatePost.net. e-mail:eric.roston@duke.edu

\title{
Beyond discord
}

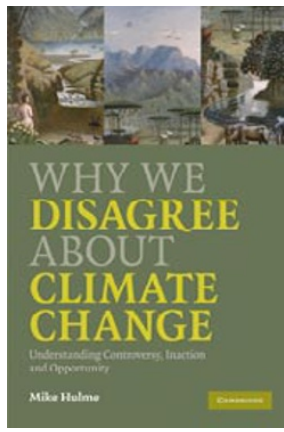

\section{WHY WE DISAGREE ABOUT CLIMATE CHANGE: UNDERSTANDING CONTROVERSY, INACTION AND OPPORTUNITY}

\author{
by Mike Hulme \\ Cambridge University Press: 2009. 432pp. $£ 17.99$
}

\section{Contention can be an opportunity to connect, rather than an obstacle to engaging with climate change.}

Why can't we all just get along? Do you mean that ExxonMobil, Shell and BP aren't entirely to blame for all the controversy and inaction on climate change? In his latest book, Why We Disagree About Climate Change, Mike Hulme - a professor in the School of Environmental Sciences at the University of East Anglia - uses such questions to drive a radical rethink on how we engage with this imperative issue. Hulme explores how our beliefs and relationships with the climate shape our priorities, and he challenges readers to connect with their own internal sources of contention and contradiction rather than those that conceivably lie with some distant nefarious villain.

In doing so, he successfully argues that these explorations can inspire a collective change in communication. "Solving climate change should not be the focus of our efforts any more than we should be 'solving' the idea of human rights or liberal democracy," he writes. "It really is not about stopping climate chaos. Instead, we need to see how we can use the idea of climate change to rethink how we take forward our political, social, economic and personal projects over the decades to come." But Hulme is not merely advocating intellectualism. Rather, he ultimately issues a John F. Kennedy-like call to action: "We need to ask not what we can do for climate change, but to ask what climate change can do for us."

Throughout the book, Hulme prompts us to move beyond thinking about climate change as a solely physical phenomenon, and to begin conceiving it as a construction through which we express our values, perspectives, beliefs and ideas. "Climate change has more potency now as a mobilising idea than it does as a physical phenomenon. Ideas can be used, but they can't be solved," writes Hulme.

Why We Disagree About Climate Change builds an intriguing understanding of these interactions through a carefully constructed volume. It does have two particular shortcomings, however. In places, the structure and organization are jumbled as Hulme privileges certain themes at the expense of others. For example, the chapter on history - which traces the 'discovery' of climate change through the physical sciences - is meticulous, but it wholly overlooks how the social sciences and humanities have shaped the 'discovery' of climate change as a mobilizing idea. Why not take a multi-faceted historical account of this interdisciplinary phenomenon? The focus on advancements merely in the physical sciences represents an opportunity lost.

And though the book's title is attentiongrabbing, it doesn't really reflect the main theme. Hulme effectively portrays disagreement as a productive process rather than a bothersome obstacle, and he makes a great effort to thread in questions about 'why we disagree' by way of boldtype statements peppered throughout the chapters. But it seems misleading to suggest that disagreement is the post to which the rest of the discourse on climate change is tethered. The comments interspersed in the text could be extracted to make a little book of climate aphorisms for daily life; however, I suspect that Hulme's volume would function as a coherent tract even without them.

Overall, Hulme articulates quite complex arguments in a remarkably clear and effective manner. He not only covers a lot of ground, but by avoiding an overly compartmentalized approach he achieves a great deal of connectivity throughout the book. For those who are regularly immersed in the social sciences literature on climate change, the content itself may not hold many surprises. But Hulme's approach makes these arguments accessible and meaningful for a wider audience, and this tome could also serve as a great teaching text. Through the book, Hulme makes important contributions to continued understanding of environmental, cultural, political and physical - eminently interdisciplinary - aspects of climate change. As more citizens, students, scientists and policy players read it, Why We Disagree About Climate Change is very likely to be an important and 'discernible influence' on the ways we think about and discuss global change, and how we plan to engage with it.

Published online: 16 July 2009

doi:10.1038/climate.2009.70

\section{Maxwell T. Boykoff}

Max Boykoff is a research fellow in the Environmental Change Institute at Oxford University.

e-mail: maxwell.boykoff@eci.ox.ac.uk 